\title{
Encapsulation of clozapine into polycaprolactone nanoparticles as a promising strategy of the novel nanoformulation of the active compound
}

\author{
Sylwia Lukasiewicz • Antoni Mikołajczyk • \\ Marta Szczęch • Krzysztof Szczepanowicz • \\ Piotr Warszyński • Marta Dziedzicka-Wasylewska
}

Received: 5 March 2019 / Accepted: 18 June 2019 / Published online: 3 July 2019

(C) The Author(s) 2019

\begin{abstract}
Clozapine (CLO), an atypical antipsychotic used in the clinic for treatment of schizophrenia, has a well-known efficacy, but its general use in clinical practice is limited because of the risk of serious side effects. Therefore, in the present work, we focused on the encapsulation of CLO into polymeric polycaprolactone nanoparticles (PCL NPs) and studies of interactions of this nanoformulation with model cells. Two types of clozapine PCL NPs (CLO-PCL NPs), pegylated and non-pegylated, were obtained by nanoemulsion templating method. The complex interactions of these NPs with three model cell lines (HEK 293, human embryonic kidney cell line; RAW 264.7, murine macrophage cell line; hCMEC/D3, model of blood-brain barrier, BBB) were studied. Cell viability, cellular uptake of NPs, NO release, expression of proinflammatory agents and transcytosis experiments were performed. Pegylated CLO-PCL NPs showed better results in the tests performed in the present study, in comparison to non-pegylated ones: they are not toxic to model cells; pegylated outer surface protected from their fast uptake by macrophages; they were not immunogenic; transcytosis experiments pointed to their ability to
\end{abstract}

S. Łukasiewicz $(\bowtie) \cdot$ A. Mikołajczyk •

M. Dziedzicka-Wasylewska

Department of Physical Biochemistry, Faculty of Biochemistry, Biophysics and Biotechnology, Jagiellonian University, 7

Gronostajowa Street, 30-387 Krakow, Poland

e-mail: sylwia.lukasiewicz@uj.edu.pl

M. Szczęch · K. Szczepanowicz • P. Warszyński

Jerzy Haber Institute of Catalysis and Surface Chemistry PAS,

30-239 Krakow, Poland cross a model BBB. The results obtained in the present study indicate that pegylated CLO-PCL NPs are promising carrier for antipsychotic drugs directed to cross BBB. The experiments were conducted using only in vitro models but they provide valuable data in the field of nanotechnology which can be used in novel molecular pharmacology.

Keywords Clozapine - Blood-brain barrier . Nanoparticles · Nanomedicine $\cdot$ Immune cells · Polycaprolactone $\cdot$ Molecular pharmacology

\section{Introduction}

Over the past decades, nanomaterials attract most attention due to the possibility of their biomedical applications. Nanoparticles (NPs) can constitute useful tool for selective transportation of lipophilic, poorly watersoluble or even water-insoluble active compounds. Such strategy allows to maintain the desired properties of the drugs by protection from the unfavourable biological environment (Anton et al. 2009; Maghraby et al. 2006; Mainardes and Silva 2004). It is also known that, in addition to influencing the cellular uptake, particle size can also influence drug loading, drug release and the stability of NPs (Mottaghitalab et al. 2015). Other important advantages of NPs are extending drug prevalence in the organism, decreasing its degradation ratio and potential to modify the NPs structure, so they can become specific and able to reach appropriate targets (Muthupandian et al. 2018; Saravanan et al. 2014; 
Wilczewska et al. 2012; Khan et al. 2015). Many techniques were described for modification of different surfaces to enable them to work as so-called surface capsules (Zhukova and Skorb 2017). In this way nanocarriers can be specifically developed to achieve an "intelligent targeting" and controlled release. Development of nanostrategies in controlled drug delivery systems has been extensively reviewed (Ghadiri et al. 2017; Farokhi et al. 2016; Mottaghitalab et al. 2015; Khan et al. 2012; Alibolandi et al. 2014, 2016). Various types of nanoformulations have been described as potential nanocarriers. However, polymeric NPs demonstrate better reproducibility and stability profiles than others (Abedini et al. 2018). The present study focuses on biocompatible polymeric nanoparticles made of polycaprolactone (PCL). PCL NPs are characterized by a diameter lower than $100 \mathrm{~nm}$ and ability of passive targeting and sustained drug release (Kim et al. 2015). What is more, over the last few years, a significant necessity emerged to evaluate PCL NPs possible pharmaceutical applications in drug delivery systems, due to their ability to transport variety of hydrophobic drugs and relatively lower cost of production and more satisfying biocompatibility (Peng et al. 2015).

One of the crucial challenges in therapy is to determine how efficient PCL NPs can penetrate desired tissue at therapeutically effective dose. Studies on the possible use of PCL NPs loaded with cytostatic drugcarboplatin for intranasal delivery have shown satisfying capability of permeation through nasal mucosa without any damaging effect on the tissue. Furthermore, they proved similar drug release rates in both in vivo and in vitro studies against human glioblastoma cells LN229 (Lupi et al. 2014). Additionally, study on pegylated PCL NPs with encapsulated neuroprotective compound (NAP) has showed very promising intranasal administration via clathrin-/caveolae-mediated endocytosis, as well as biodistribution in the rat brain. Therefore, they may serve as an opportunity for effective treatment of neurodegenerative diseases such as Alzheimer's disease (Agrahari et al. 2016).

PCL NPs have also been tested for their possible use in treatment of conditions beyond CNS. Studies demonstrated that nanoparticles smaller than $100 \mathrm{~nm}$ were absorbed easier by immune cells like macrophages or dendritic cells in areas of inflammation. It provides an opportunity to use encapsulated therapeutics in treatment of diseases such as ulcerative colitis (UC) and Crohn's disease (CD) (Zhang et al. 2002).
Recently, polymeric NPs were tested as potential nanoadjuvants in creating vaccines inducing prolonged resistance (Alexis et al. 2008; Mathaes et al. 2014). PCL NPs with encapsulated anatoxin tetanus toxoid (TT) have been used to determine macrophage polarization and antigen presentation mechanism by human monocyte-derived macrophages. The results of the trial showed that small NPs (range $61.2 \mathrm{~nm}$ ) caused constant and prolonged both humoral and cellular immunoresponse against TT. It may be a symptom that this type of immunization - via long time of degradation and high biocompatibility of PCL NPs - has a great potential as single shot vaccines (Mathaes et al. 2014).

The nanostrategy is also very promising, especially in case of neurodegenerative, neuropsychiatric and other brain diseases where the delivery of active compound to the desired brain regions remains still a big challenge. The main reason of insufficient treatment of brain diseases is the presence of blood-brain barrier (BBB). Some nanostrategies developed to overcome the problem have been described (Ghadiri et al. 2017; Yeste et al. 2018). One of the brain diseases still without satisfactory therapy is schizophrenia. It is a serious disorder of brain and mind that affects ca. $1 \%$ of human population (Stępnicki et al. 2018). Schizophrenia finds place within 10 diseases that cause the greatest social disability and it generates enormous costs of therapy. It is an extremely devastating, complex disease manifested by both behavioural and cellular dysfunctions. The cause of schizophrenia is still not fully elucidated; dysregulation of few neurotransmission systems is taken into account, including glutamatergic, as well as dopaminergic and serotonergic systems (Ali et al. 2017). Various antipsychotic drugs are available and used in the clinic, but it has been widely demonstrated that between $20 \%$ to even $60 \%$ of patients with schizophrenia do not respond sufficiently to conventional treatments (Howes et al. 2017).

Clozapine (CLO, dibenzodiazepine) is a multireceptorial atypical antipsychotic compound with well-documented efficacy, also in the treatment-resistant schizophrenia (Berardis et al. 2012). The precise mechanism of action of the drug is still unknown; however, its therapeutic effects are probably mediated by dopaminergic and serotonergic activity (Meltzer and Huang 2008). Although CLO is well absorbed after oral administration, it undergoes extensive first-pass hepatic metabolism, resulting in poor oral bioavailability (Kadam et al. 2012; Manjunath and Venkateswarlu 2005). In addition, its low plasma half-life points towards 
extensive metabolic clearance (Kadam et al. 2012). One of the major limitations of treatment with CLO is inefficient delivery of the drug to the appropriate part of the brain.

Although CLO has well-known and documented antipsychotic efficacy (it is effective in the treatment of both positive and negative symptoms of schizophrenia and has low extrapyramidal side effects (Essali et al. 2009; Warnez and Alessi-Severini 2014)), its clinical use is diminished because of multitude of adverse effects arising from its long-term administration (i.e. arrhythmias, weight gain, metabolic dysfunction linked to diabetes, myocarditis, cardiomyopathy and, above all, agranulocytosis (Warnez and Alessi-Severini 2014; Berardis et al. 2018)). Although, FDA (Food and Drug Administration) and the drug's manufacturer have strengthened warnings that a potentially fatal myocarditis may occur when taking CLO (Berardis et al. 2012), it still remains the drug of choice in treatment-resistant schizophrenia (Remington et al. 2016). It has been demonstrated that CLO is more effective than any other of first-generation (FGA) or second-generation antipsychotics (SGA) in the treatment of resistant schizophrenia and it is also useful in other conditions (Siskind et al. 2016; De Berardis et al. 2013). It has been estimated that almost two thirds of those patients who do not respond adequately to treatment with FGAs or other SGAs may respond adequately to treatment with CLO (Essali et al. 2009). Undoubtedly, it is a very effective drug in everyday clinical practice and many patients who tolerate it will experience remarkable relief of symptoms (Orsolini et al. 2016). However, there are many patients who do not tolerate this drug. Considering the above features of CLO, it is not surprising that there is a need to find a more efficient and safer route of administration of this drug Therefore, the development of new form of CLO, allowing its controlled release, which may improve its therapeutic potential, is one of the most significant topics for modern neuroscience. Recently, several different nanoformulations of CLO have been presented (Moraes et al. 2016; Kirbay et al. 2017; Vieira et al. 2016; Panda et al. 2016; da Costa Güllich et al. 2015). The findings show that various CLO nanoformulations may lead to decrease of side effects suggesting that the drug, when loaded to different nanocapsules, is able to mitigate the harmful effects (da Costa Güllich et al. 2015).

In the present work, CLO was encapsulated into polycaprolactone polymeric nanoparticles (CLO-PCL
NPs). Two types of CLO-PCL NPs (non-pegylated and pegylated) were synthesized by nanoemulsion templating method. Pegylation is well-documented modification of outer surface of NPs which minimizes the fast clearance of NPs from the blood and makes particles invisible to the immune system. PEG is an uncharged, hydrophilic polymer, whose extensive hydration, high conformational flexibility and high chain mobility account for a steric exclusion effect (Torchilin and Trubetskoy 1995). The protein resistance of PEGbased coatings depends on both the length of chains and their density (Milton Harris and Chess 2003; Vermette and Meagher 2003; Halperin 1999; Zhu et al. 2001). Moreover, the interactions of obtained clozapine PCL nanoparticles (CLO-PCL NPs) with various model cells (HEK 293, RAW 264.7, hCMEC/D3) were studied. The biocompatibility, immunomodulatory effects, uptake, endocytosis pathways, phagocytic potential and transcytosis were estimated.

\section{Experimental section}

Materials

\section{CLO-PCL-NPs preparation}

Clozapine was received from Tocris. Polycaprolactone PCL $(\mathrm{Mw} \sim 10,000)$ and poly(ethylene glycol)-blockpoly $(\varepsilon$-caprolactone) methyl ether PCL-b-PEG (PCL $\mathrm{Mw} \sim 13,000$, PEG Mw 5000), poly(ethylene glycol), TWEEN® 20 (sorbitan monolaurate) and Span® 20 (sorbitan monolaurate) were obtained from Sigma-Aldrich. Toluene was purchased from Avantor Performance Materials. Distilled water was from the DirectQ 5UV purification system from Millipore. All chemicals were used as received without further purification.

\section{Materials for cell culture assays}

Mouse murine macrophage cell line (RAW 264.7) was obtained from Sigma-Aldrich. The immortalized human cerebral microvascular endothelial cells, D3 clone (hCMEC/D3) was kindly provided by Prof. Babette Weksler (Cornell University, NY). Human embryonic kidney 293 (HEK 293) cells were obtained from the American Type Culture Collection. The cell culture materials, including heat-inactivated foetal bovine 
serum (FBS), EDTA/Trypsin solution, endocytosis inhibitors (chlorpromazine, amiloride, filipin III), rat collagen, TRI-Reagent, DMEM, MEM, F12 media and MTT (3-[4,5-dimethylthiazol-2-yl]-2,5 diphenyl tetrazolium bromide), were purchased from Sigma-Aldrich. The cell culture EGM-2 media with all supplements were from Lonza. Lactate dehydrogenase (LDH) Cytotoxicity Detection Kit was from Clontech Laboratories. Vybrant Phagocytosis Kit, Griess Reagent Kit for Nitrite Determination were from Molecular Probes (Thermo Scientific). All molecular biology reagents, as well as Luminaris HiGreen qPCR Master Mix, were obtained from Thermo Scientific. Oligonucleotides were synthesized by Genomed S.A.

\section{Methods}

\section{CLO-PCL-NPs preparation}

CLO loaded in polymeric nanocarriers were prepared according to the method described previously (Szczęch et al. 2017), by nanoemulsion templating method. Two types of CLO polymeric nanocarriers were synthesized: pegylated and non-pegylated. The nanoemulsion of toluene containing CLO $(0.6 \mathrm{mg} / \mathrm{ml})$ mixture of polymers PCL-b-PEG $(0.13 \mathrm{mg} / \mathrm{ml}$ with PCL $2.88 \mathrm{mg} / \mathrm{ml})$ or bare PCL ( $3 \mathrm{mg} / \mathrm{ml})$, in water stabilized by TWEEN ${ }^{\circledR} 20$ and Span® 20 surfactants, was formed by the PIC technique (phase inversion composition) at constant temperature. Nanoemulsion was composed as follows: $20 \%(v / v)$ oil phase, 5\% (v/v) Tween20/Span20 (HLB = 13.5) and $75 \%(v / v)$ water. After preparation of nanoemulsion, organic solvent (toluene) was removed by evaporation, while surfactants were removed by dialysis. Fluorescently labelled NPs were prepared by encapsulation of fluorescent dye (Coumarin-6) into formed NPs. Coumarin-6 was dissolved in the oil phase at concentration $0.5 \mathrm{mg} / \mathrm{ml}$ before the nanoemulsification process.

\section{CLO-PCL NPs characterization}

The hydrodynamic size of prepared CLO-PCL NPs was measured by the dynamic light scattering (DLS) technique using Zetasizer Nano ZS, Malvern Instruments. The values were received as an average of at least three subsequent measurements with 20 runs. The concentration of synthesized clozapine nanocarriers was measured by nanoparticle tracking analysis (NTA) using NS500 NanoSight Malvern Instruments. All measurements were evaluated at $25^{\circ} \mathrm{C}$. To evaluate the stability of the synthesized NPs, their hydrodynamic size was monitored in time during storage in the preparation buffer (water) as well as in cell culture media (DMEM containing $10 \%$ FBS). All measurements were evaluated at $25^{\circ} \mathrm{C}$.

\section{Cell culture}

RAW 264.7 cells were grown in DMEM supplemented with $1 \%$ L-glutamine, high glucose and $10 \%$ heatinactivated foetal bovine serum (FBS). HEK 293 cells were grown in MEM supplemented with $1 \% \mathrm{~L}$ glutamine and $10 \%$ heat-inactivated FBS. The hCMEC/D3 cell line was grown in EBM-2 (endothelial cell basal medium) supplemented with components obtained from the manufacturer (human epidermal growth factor (hEGF), vascular endothelial growth factor (VEGF), R3-insulin-like growth factor-1 (R3-IGF-1), ascorbic acid, hydrocortisone, human fibroblast growth factor-beta (hFGF- $\beta$ ), heparin, gentamicin/ amphotericin-B (GA) and 10\% FBS. To provide optimal growth conditions, the hCMEC/D3 cells were seeded on tissue culture plates, dishes or flasks coated with rat collagen (final protein concentration $150 \mu \mathrm{g} / \mathrm{ml}$ ). All the cell lines were cultured at $37{ }^{\circ} \mathrm{C}$ in a humidified incubator with a $5 \% \mathrm{CO}_{2}$ atmosphere. The medium was changed every 3-4 days. hCMEC/D3 cells were used at passages 26-34. After hCMEC/D3 cell culture conditions were established, the cell marker characteristic for BBB cells was established as described previously [52]. Two days before the MTT, LDH and NO tests, cells were seeded into the appropriate 96-well plates at a density of $3 \times 10^{4}$ cells per well. For flow cytometry and qPCR measurements cells were seeded into 6-well plates at a density of $3 \times 10^{5}$ cells per well. Five days before transcytosis experiments, the hCMEC/D3 cells were seeded $13 \times 10^{3}$ cells per well into appropriate 96well plates (HTS FluoroBlokTM Multiwell Insert System) on collagen type I-coated Transwell membrane permeable supports with $3 \mu \mathrm{m}$ (96-well plate) or $48.5 \times 10^{3}$ cells in 24-well plates (Falcon Cell Culture Inserts) on collagen type I-coated $1 \mu \mathrm{m}$ (24-well plate) pore size. Before Vybrant Phagocytosis test cells were seeded in 96-well microplates-1 $1 \times 10^{5}$ RAW 264.7 cells per well. 
Cell viability and cytotoxicity assays

\section{MTT reduction test}

MTT reduction test was performed to evaluate RAW 264.7 and HEK 293 cells viability. Different types of CLO-PCL NPs, pegylated and non-pegylated were added in variable doses to the fresh medium into each well, respectively. Doses of ca. 16,500, 7000 and 3500 NPs per cell were used. Twenty-four hours cells were incubated with the NPs, then medium was aspirated, and replaced with $50 \mu \mathrm{l}$ of $0.5 \mathrm{mg} / \mathrm{ml}$ MTT (3-(4,5-dimethylthiazol-2-yl)-2,5-diphenyltetrazolium bromide) resuspended in serum-free medium. After $4 \mathrm{~h}$ incubation at $37{ }^{\circ} \mathrm{C}$ in a $5 \% \mathrm{CO}_{2}$ atmosphere, medium was removed and $100 \mu \mathrm{l}$ of DMSO was added to each well. After 10 min of incubation with shaking, the absorbance was measured at $570 \mathrm{~nm}$ using a microplate reader (TECAN Infinitive M200 Pro). Untreated cells incubated only with fresh medium constituted a control. Six replicates for each types and dose of CLO-PCL NPs were done. Presented result reflect the effect obtained from 5 independent experiments.

CellTiter-Blue ${ }^{\circledR}$ Cell Viability Assay The hCMEC/D3 cell viability was established using the CellTiter-Blue ${ }^{\circledR}$ Cell Viability Assay. Various doses (ca. 16,500, 7000, 3500 NPs per cell) of obtained CLO-PCL NPs were added into each well, respectively. Twenty-four hours cells were treated with particles. Then, after medium aspiration, the freshly prepared complete medium (100 $\mu$ l per well) supplemented with CellTiter-Blue reagent $(20 \mu \mathrm{l}$ per well) was added to each well. The fluorescence signal was acquired (TECAN Infinitive200 excitation wavelength $560 \mathrm{~nm}$; emission wavelength $590 \mathrm{~nm}$ ) after $3 \mathrm{~h}$ incubation at standard culture condition. Control experiments determine untreated cells. Six replicates for each type of CLO-PCL NPs were measured. The final results reflect the average cell viability acquired from 4 independent experiments.

\section{LDH cytotoxicity detection kit}

The LDH (lactate dehydrogenase) released into the cell culture medium is correlated with cell membrane destabilization and destruction and marks cytotoxicity of tested nanomaterials. The assay was conducted in RAW 264.7 and HEK 293 cells after $4 \mathrm{~h}$ of incubation with synthesized CLO-PCL NPs (doses were analogous to the MTT assay). 96-well plates were centrifuged at $250 \mathrm{~g}$ for $7 \mathrm{~min}$. Then, $50 \mu \mathrm{l}$ of culture medium was added to $50 \mu$ of the reaction mixture and incubated for $30 \mathrm{~min}$ in the dark at room temperature. The colorimetric reaction products were monitored by absorbance measurements at $490 \mathrm{~nm}$ wavelength (with the reference wavelength at $610 \mathrm{~nm}$ ) (TECAN Infinitive200). Negative control was determined for untreated cells (spontaneous LDH release). Positive control-maximum LDH release level - was measured after addition of Triton X100 (causing cell death) to appropriate wells. Six replicates for each types and dose of CLO-PCL NPs were done. Presented result reflects the effect obtained from 4 independent experiments.

\section{Flow cytometry experiments}

Flow cytometry was adopted to the quantitative cellular uptake measurements. The experiments were performed for different types of obtained CLO-PCL NPs in various cell lines: RAW 264.7 and hCMEC/D3. Cells were cultured in the standard condition and before the experiment, CLO-PCL NPs (fluorescently labelled with coumarin) were added to the fresh full medium (at various doses ca. 100, 500, 1000, 2000, 3500, 5000 NPs per cell, respectively) and incubated for $4 \mathrm{~h}$ at $37^{\circ} \mathrm{C}$, in a $5 \%$ $\mathrm{CO}_{2}$. Non-absorbed NPs were removed during rigorous washing (4 times using cold PBS, phosphate buffer saline, $\mathrm{pH}$ 7.4). For the measurements, cells were suspended in $300 \mu \mathrm{l}$ of cold PBS. To establish which endocytosis pathway is engaged in the process, cells were pre-incubated $(1 \mathrm{~h})$ under standard culture condition with specific endocytosis inhibitors (chlorpromazine (CPZ $8 \mu \mathrm{g} / \mathrm{ml})$, filipin III $(1 \mu \mathrm{g} / \mathrm{ml})$ and amiloride $(50 \mu \mathrm{M})$, respectively). The uptake experiments were done using BD FACSCalibur flow cytometer and CellQuestPro software. Ten thousand events were acquired for each sample. Treatment of the cells with $0.015 \mathrm{M} \mathrm{NaCl}$ as well as non-fluorescent CLO-PCL NPs determines the background (autofluorescence). Two replicates for each CLO-PCL NPs were measured. The obtained results represent the average of 4 independent experiments.

\section{No determination test}

For determination of NO released by RAW 264.7 cells as a result of interaction with CLO-PCL NPs, Griess Reagent Kit for Nitrite Determination was used, 
according to the manufacturer's protocol. Cells were incubated for $4 \mathrm{~h}$ under standard culture conditions in the presence of various types and doses of CLO-PCL NPs (ca. 16,500, 7000, 3500 NPs per cell). After incubation, $75 \mu$ of supernatant from each well was mixed with $10 \mu \mathrm{l}$ of Griess Reagent and incubated for $30 \mathrm{~min}$ in dark at room temperature. The reference sample was prepared by mixing $10 \mu \mathrm{l}$ of Griess Reagent and $140 \mu \mathrm{l}$ of deionized water. The NO release was detected by measurement of absorbance at $548 \mathrm{~nm}$ using a microplate reader (TECAN Infinitive200). Untreated cells incubated with fresh medium constituted a control. Six replicates for each CLO-PCL NPs dose were measured. The final results reflect the average acquired from 3 independent experiments.

\section{Vybrant phagocytosis assay}

A phagocytosis assay was conducted according to the manufacturer's protocol. Obtained CLO-PCL NPs were added to the cells (doses of ca. 7000, 3500 NPs per cell) for $2 \mathrm{~h}$ in standard culture conditions. Then, medium was removed and the cells were incubated for $2 \mathrm{~h}$ at $37{ }^{\circ} \mathrm{C}$ with fluorescein-labelled E. coli particles (HBSS buffer). Finally, the bacterial particles were aspirated and Trypan Blue (which quenched fluorescence resulting from non-internalized $E$. coli) was added to each well. Non-NPs treated cells were used as a positive and free medium as a negative control. The fluorescence measurements were performed using $488 \mathrm{~nm}$ excitation, $520 \mathrm{~nm}$ emission wavelengths (TECAN Infinitive200Pro). For each type of used NPs, 5 replicates were conducted. Final results consist the average from 3 independent experiments.

qPCR (quantitative real-time PCR) experiments

The various doses (ca. 500, 2000, 3500 NPs per cell) of CLO-PCL NPs were incubated with RAW 264.7 cells at $37{ }^{\circ} \mathrm{C}$ in a $5 \% \mathrm{CO}_{2}$ incubator for $4 \mathrm{~h}$ in the complete fresh medium. Total RNA was isolated using TriReagent and phenol-chloroform extraction. One microgram of total RNA was reverse transcribed to cDNA and used in the qPCR reaction with the specific primers (Table 1) and Luminaris HiGreen qPCR Master Mix (Eco $^{\text {TM }}$ Real-Time PCR System-Illumina). GAPDH was reference gene, untreated cells were the reference sample.
Table 1 Specific primers used in qPCR reactions

\begin{tabular}{ll}
\hline Primer & Sequence \\
\hline GAPDH-for & TCAACGGCACAGTCAAGG \\
GAPDH-rev & ACTCCACGACATACTCAGC \\
IkB $\alpha$ FOR & CTTGGTGACTTTGGGTGCTGAT \\
IkB $\alpha$ REV & GCGAAACCAGGTCAGGATTC \\
iNOFOR & TCCTACACCACACCAAAC \\
iNOREV & CTCCAATCTCTGCCTATCC \\
IL-6FOR & TTCTCTGGGAAATCGTGGAAA \\
IL-6REV & TCAGAATTGCCATTGCACAAC \\
TNF- $\alpha$ FOR & CCCTCACACTCAGATCATCTTCT \\
TNF- $\alpha$ REV & GCTACGACGTGGGCTACAG \\
\hline
\end{tabular}

CLO-PCL-NPs transcytosis experiments

Fresh culture medium containing coumarin-labelled CLO-PCL NPs in dose ca. 5000, NPs per cell were prepared and used in transcytosis experiments. Briefly, the medium was added to apical side of hCMEC/D3 monolayer. The basolateral part of chamber comprise the fresh medium without NPs. The signal comes from the coumarin was acquired from the basolateral part of the plate every hour. In case of transwell inserts with $1 \mu \mathrm{m}$ pore size (24-well plate), the basolateral medium $(100 \mu \mathrm{l})$ was received at each time point, transferred to a 96-well plate and measured. Fluorescence was measured at $485 \mathrm{~nm}$ excitation and $520 \mathrm{~nm}$ emission wavelength (TECAN Infinitive200). Additionally two types of control experiments - where signal was acquired from wells with non-NPs treated cells as well as from empty (with no cells) transwells - were performed. Two replicates for each type of NPs were done. Final results reflect the effect from 4 independent experiments.

Statistical analysis

Final data are presented as the mean \pm standard error (SEM). The statistical significance was determined using the parametric Student's $t$ test and nonparametric Mann-Whitney $U$ test; $* p<0.05$, $* * p<0.01, * * * p<0.001$.

\section{Results and discussion}

Improved pharmacotherapy for schizophrenia still remains a key challenge for molecular pharmacology. 
Finding a new active compound which will be effective in the clinic and at the same time will not cause serious side effects is difficult to achieve. Therefore, we focused on the obtaining novel nanoformulation of well-known antipsychotic compound such as clozapine (CLO). The new strategy may be more safe (not generating serious side effects) and would contribute to improvement of therapeutic potential of the drug.

The synthesized CLO-PCL NPs were characterized by measurements of their size (i.e. hydrodynamic diameter), concentration and zeta potential as summarized in Table 2. For the synthesis of pegylated NPs, we used the mixture of two polymers: PCL and its copolymer PCLb-PEG with the PEG (MW 5000). These components, compared to the non-pegylated ones where we used the only PCL, were added together to the oil phase for the formation of polymeric cores. The differences between the mean size of CLO-PCL-PEG and CLO-PCL NPs may be caused by different amounts of PCL/PCL-bPEG and single PCL dissolved in the nanoemulsion droplets. That is why after the evaporation of an organic solvent, we obtained differences in the mean size of particles due to the method of their preparation. We could observe the size increasing if we will modify the PCL NPs by pegylation after their synthesis. However, we performed two different syntheses. The PDI index for both type of NPs below 0.3 which confirm monodisperse character of synthesized nanoparticles. The stability of obtained NPs in cell cultured media containing $10 \%$ FBS was evaluated. The nanomaterials were stable in mentioned above condition since they retained their size without significant changes for at least $48 \mathrm{~h}$ [51]. Long-term stability tests were performed in preparation buffer (water), and up to 6 months, we did not observe significant changes in the hydrodynamic size and zeta potential of tested nanoparticles.

\section{Cytotoxicity of CLO-PCL NPs}

Biomedical applications of CLO-PCL NPs require wide investigation which enable the description of the interaction between particles and model cells. Nanomaterial toxicity is a major factor in determining its applicability for drug delivery. Therefore, the cytotoxicity of prepared CLO-PCL NPs was evaluated. MTT as well as LDH assays were adopted to the study. The results are similar for both investigated cell lines, RAW 264.7 and HEK 293, and indicate that viability of the cells strongly depends on pegylation of CLO-PCL NPs. Estimated level of cells viability for pegylated CLO-PCL NPs is near $100 \%$. The highest undesired effect was observed for the highest dose of unmodified CLO-PCL NPs (Fig. 1a, b).

The most probably, this effect might be caused by free CLO which may have spontaneously released from non-PEG covered particles. This interpretation is in a way confirmed by the results obtained for free PCL NPs (data not shown) since we did not see any difference in cells viability (ca. 80-90\%) between pegylated and nonpegylated carriers. Cytotoxicity of nanomaterials mainly depends on the interaction between NPs and cell membrane and is correlated with the charge, shape, size, surface area, flexibility, surface chemical properties and amphipatic character of NPs (Nel et al. 2006; Hong et al. 2006; Lee and Larson 2008; Leroueil et al. 2008). Charged NPs interact with cell membrane mainly in the electrostatic way (Nel et al. 2006; Hong et al. 2006). The literature data connect the observed toxic effect of nanomaterials with increased adsorption of NPs (especially positively charged) on the cell membrane, decreasing of lipid density and, eventually, the plasma membrane disruptions (Verma and Stellacci 2010). Therefore, LDH release test, in which membrane integrity is assessed by monitoring the efflux of cytoplasmic lactate dehydrogenase into the cell culture medium, was performed following incubation of cells with obtained CLO-PCL NPs. Promising results (Fig. 1c, d) were obtained since we did not observe LDH release above the level characteristic for control cells. The results were similar for both cell lines (RAW 264.7 and HEK 293). Comparison of cytotoxic effects generated by various types of PCL NPs synthesized by others indicates the safe profile of the nanocarrier. Independently of modification of the kind of NPs, the viability

Table 2 Characterization of clozapine-loaded nanocarriers

\begin{tabular}{llllll}
\hline Sample code & Mean size $[\mathrm{nm}]$ & PdI & Zeta potential $[\mathrm{mV}]$ & Clozapine content [mg/l] & Concentration [NPs/ml] \\
\hline CLO-PCL-PEG & 87 & 0.215 & -22 & 10 & $4 \times 10^{11}$ \\
CLO-PCL & 99 & 0.216 & -25 & 10 & $3 \times 10^{11}$ \\
\hline
\end{tabular}



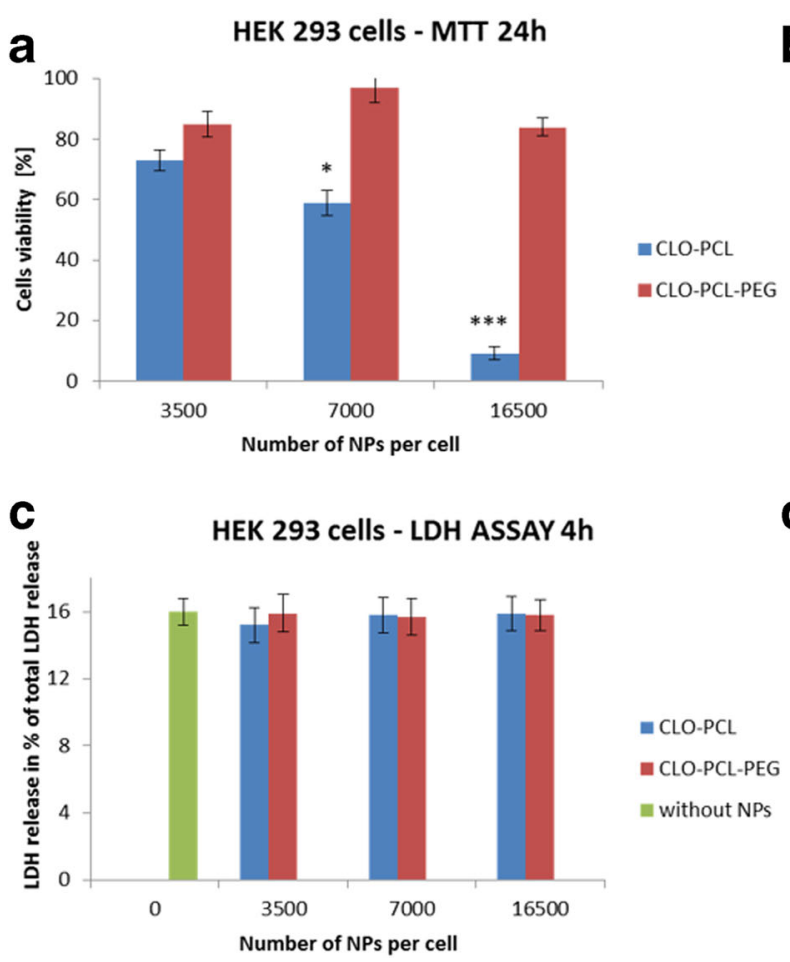

Fig. 1 Biocompatibility studies after incubation of cells with both types (non- and pegylated) CLO-PCL NPs. a MTT assay in HEK 293 cells. b MTT assay in RAW 264.7 cells. c LDH assay in HEK

of model cell was not affected (Kiran et al. 2018; Li et al. 2019; Xie et al. 2018).

\section{CLO-PCL NPs interaction with immune cells}

The design of effective nanoformulation of active compound in drug delivery systems requires wide experiments regarding of the interaction between NPs and immune cells. The nanocarriers should be designed in the way that enables to avoid opsonin adsorption (the major process which facilitates recognition and removal of NPs by phagocytic cells), to increase circulation time and to allow to achieve the preferred site of action. Moreover, nanocarriers cannot initiate immune response processes. Therefore, we performed the set of experiments (NO release, qPCR experiments that allow to detect the level of major mediators of inflammation) to characterize pro-inflammatory activity of CLO-PCL NPs. NO fulfils multiple functions in the body, one of them is participation in immune response processes. The obtained results (Fig. 2) clearly show that there was no significant increase in the level of NO released by the RAW 264.7 cells, which indicates a possible low
RAW 264.7 cells - MTT 24h
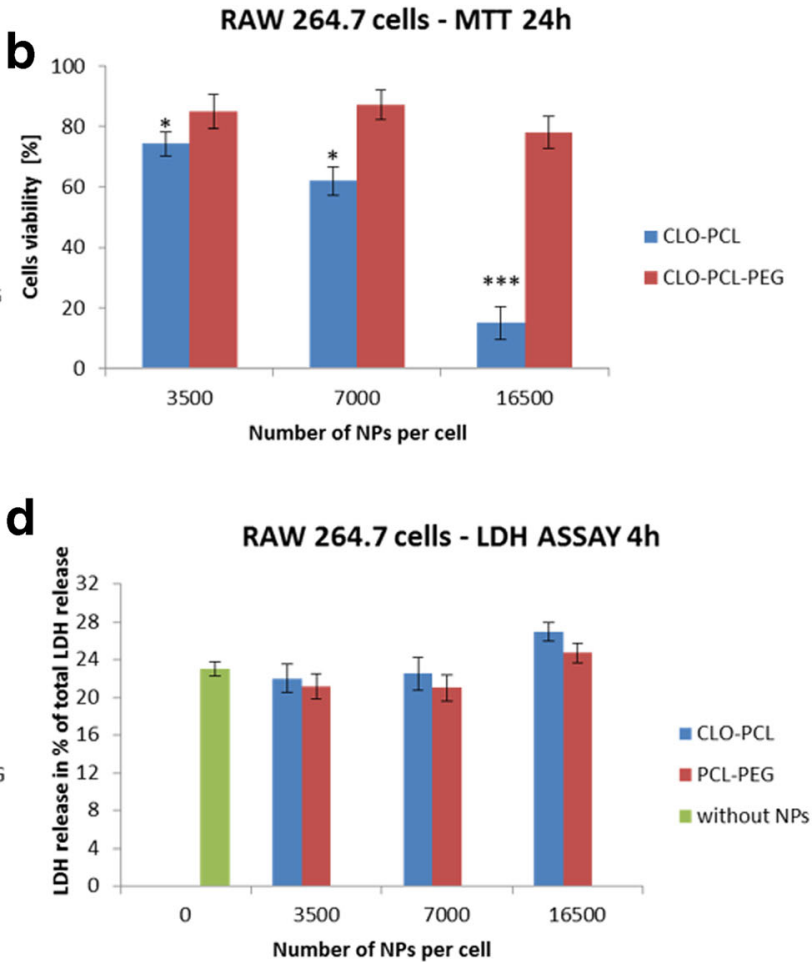

293 cells. d LDH assay in RAW 264.7 Data are presented as the means \pm standard error (SEM)

immunogenicity of the synthesized CLO-PCL NPs. Comparison of the pegylated and non-pegylated CLOPCL NPs points to better features of pegylated ones since slightly lower level of NO was detected.

Moreover, the expression of the following genes: interleukine 6 (IL-6), tumour necrosis factor (TNF- $\alpha$ ), induced nitric oxide synthase (iNOS) and inhibitory protein for the factor NF-kB ( $\mathrm{IkB} \alpha$ ) following incubation of the cells with both types of CLO-PCL NPs was examined. The reference gene was the gene for GAPDH (3-phosphoglycerate dehydrogenase) while the cells incubated without NPs constituted the reference. Due to the lack of expression of the examined genes in the reference samples, it was impossible to determine the $\mathrm{Rq}$ value; therefore, the following results illustrate the cycle number in which the fluorescence signal originating from a given gene exceeded the threshold value. The results shown in Fig. 3 indicate that for both types of CLO-PCL NPs, regardless of the used doses, two genes were expressed: $\operatorname{IkB} \alpha$ and TNF- $\alpha$. IkB $\alpha$ protects the cell by binding with the NF-kB and factor blocking its proinflammatory activity. 
Fig. 2 NO release from RAW 264.7 cells after $4 \mathrm{~h}$ incubation with both types (non- and pegylated) CLO-PCL NPs. Data are presented as the means \pm standard error (SEM)
NO DETECTION

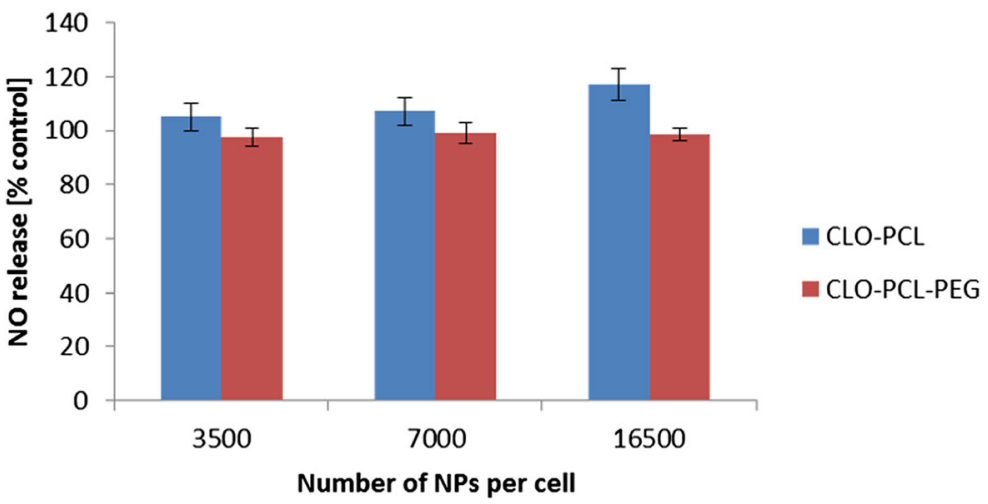

TNF- $\alpha$ is one of the most important cytokines involved in immunological processes, cellular homeostasis and tumour progression. Its expression may occur independently of the incubation with CLO-PCL NPs, as it is an indispensable factor for the proliferation and proper functioning of immune cells, including macrophages (Kulkarni and Feng 2013). This is supported by the fact that the similar level of TNF- $\alpha$ (to that recorded for pegylated CLO-PCL NPs) was also observed in the case of cells that were not incubated with CLO-PCL NPs (data not shown). Comparison of both types of CLO-PCL NPs shows slight increase in TNF- $\alpha$ expression level induced by non-pegylated NPs. Moreover, we did not detect IL-6 (one of the cytokines with the strongest proinflammatory effect) expression in case of pegylated CLO-PCL NPs. Increase of the IL-6 gene expression level in case of non-pegylated CLO-PCL NPs was observed only for higher doses of NPs (the dose-dependent effect) but still we can define the dose which was safe and did not cause expression of that gene (Fig. 3). The most probably, the undesired immunomodulatory effect detected for unmodified CLO-PCL NPs was connected with the spontaneous release of clozapine from these NPs. On the other hand, pegylation of outer surface of CLO-PCL NPs (besides other features described above) increased the thickness of the shell which prevented uncontrolled release of the drug from the particle. It has been shown recently that CLO stimulates in vivo the release of cytokines and soluble cytokine receptors (Pollmächer et al. 2001). This holds true for the tumour necrosis factor (TNF)-system, the interleukin(IL)-2-system, IL-6 and granulocyte colony-stimulating factor (GCSF) (Francesconi et al. 2018; Pollmächer et al. 2001). Moreover, it is likely that TNF- $\alpha$, IL- 6 and other cytokines are involved in metabolic (weight gain, diabetes), cardiac (myocarditis), CNS (sedation) and other rare side
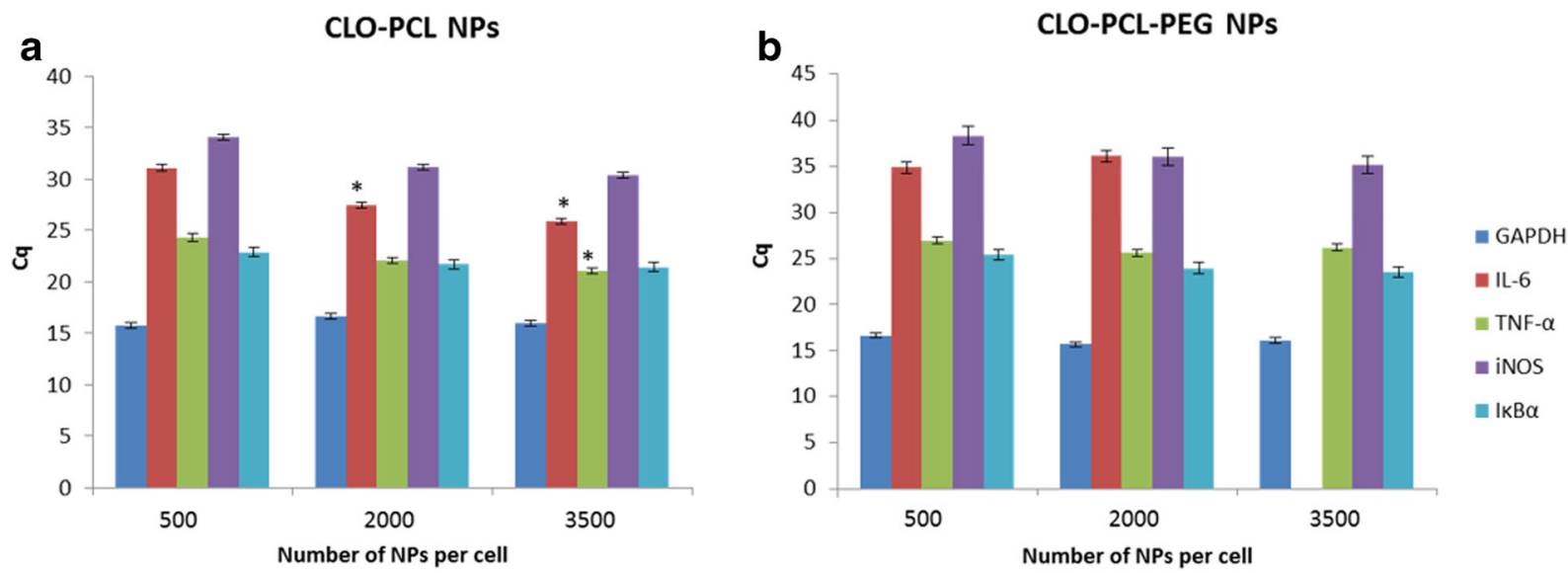

Fig. 3 qPCR experiments. Expression level of GAPDH, IL-6, TNF- $\alpha$, iNOS and IkB $\alpha$ determined by Cq. a $4 \mathrm{~h}$ incubation with CLO-PCL NPs. b $4 \mathrm{~h}$ incubation with CLO-PCL-PEG NPs. Data are presented as the means \pm standard error (SEM) 
effects (Francesconi et al. 2018). Altogether, the obtained results indicate that pegylated CLO-PCL NPs are safe CLO nanoformulation, irrespectively of the dose used, since they do not initiate an immune response in the RAW 264.7 cells, which is the most important finding of this part of the study.

Additionally, we determined the ability of both types of the CLO-PCL NPs to modulate the phagocytic potential of the RAW 264.7 cells. The obtained results show a relationship between the used NPs dose and the efficiency of the phagocytosis, especially for non-pegylated CLO-PCL NPs. Moreover, unmodified CLO-PCL NPs showed tendency to reduction of the process (Fig. 4).

It has been shown that CLO reduced the phagocytic activity of macrophages (Chen et al. 2013). Hence, probably the observed effect may be connected with action of clozapine (released from the nanocarrier) and not the carrier alone. The PEG layer is responsible for slowing the process of clozapine release from the carrier.

As it was mentioned above, pegylation is one of the available methods to prevent serum protein adsorption and non-specific bindings that promote fast NPs uptake. It is well known that the mechanism of NPs uptake is cell type specific (Owens and Peppas 2006). Literature data indicate that the NPs uptake is mediated by a phagocytic or an endocytic process, but also a passive mode of uptake was determined (Fond et al. 2013). In the present studies, flow cytometry technique was adopted to the kind of experiments. The summary of obtained data is presented in Fig. 5. The internalization process was dose dependent. All of synthesized CLOPCL NPs were found inside the RAW 264.7 cells; however, the non-pegylated CLO-PCL NPs were internalized with increased intensity. Pegylation of the outer surface of CLO-PCL NPs diminished the process and at the same time made the nanomaterials more invisible to the immune cells.

The cellular uptake mechanism was energy-dependent, what was confirmed by experiments carried out at a lower temperature $\left(4^{\circ} \mathrm{C}\right)$ - significant inhibition of the process was recorded. To determine which pathways are engaged in the endocytosis, the experiments in with specific endocytosis inhibitors added prior to administration of the CLO-PCL NPs were done. The obtained results indicate that endocytosis via clathrin-coated vesicles played a key role in CLO-PCL NPs internalization. The results were similar to the ones described previously for other polymeric NPs (Lukasiewicz et al. 2015, 2016).

CLO-PCL NPs interaction with in vitro blood-brain barrier model

The BBB is an active interface between circulation and the central nervous system (CNS), which restricts the free movement of different substances between the two compartments and plays a crucial role in the maintenance of CNS homeostasis (Łukasiewicz et al. 2017). Recent studies showed the possibility of crossing BBB by surface modified (by targeting ligand incorporation) PCL NPs (Xin et al. 2012; Pang et al. 2008; Omarch et al. 2019). Finding an effective nanocarrier designated to controlled drug delivery in the brain tissue requires extensive studies of the interaction of the nanovehicles with the BBB. The main challenge is the achievements of brain areas by drug-conjugated NPs. To investigate the issue, first of all, we should find the most suitable BBB model which allows to obtain the best outcomes. Currently, several in vitro models of BBB are available
Fig. 4 Vybrant phagocytosis assay after $2 \mathrm{~h}$ incubation with both types (non- and pegylated) CLO-PCL NPs. Data are presented as the means \pm standard error (SEM)

\section{Vybrant Phagocytosis assay}

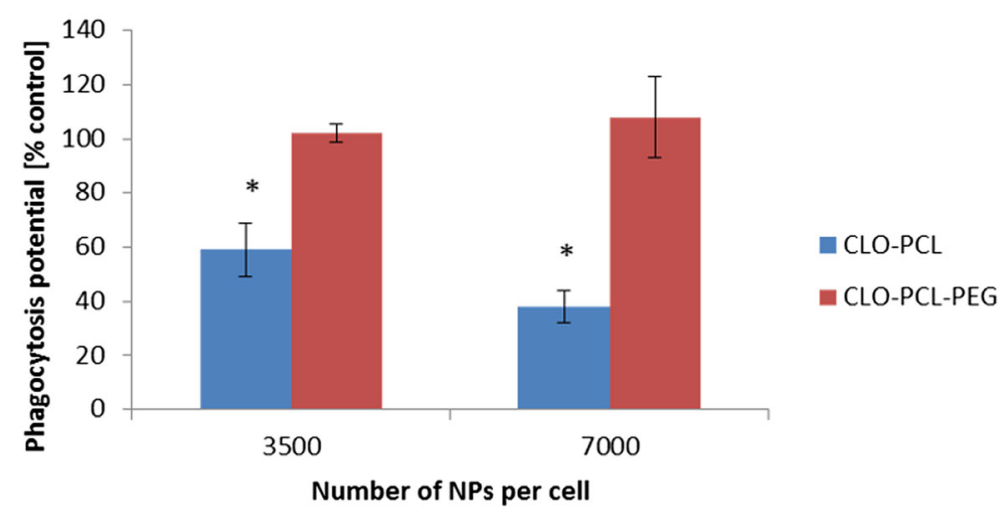


a

RAW 264.7 cells

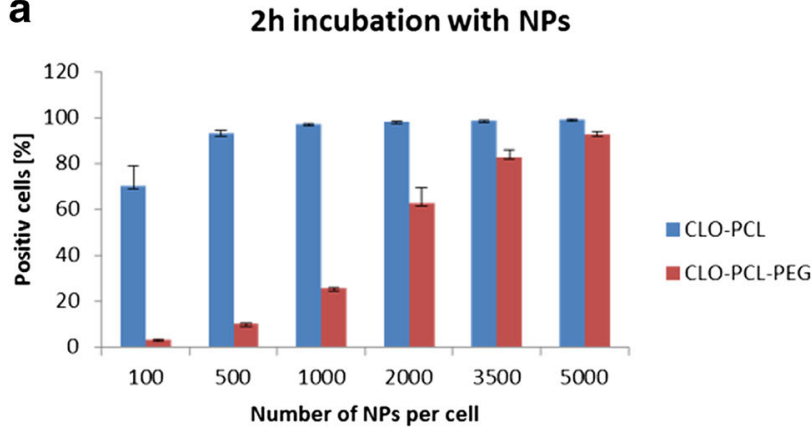

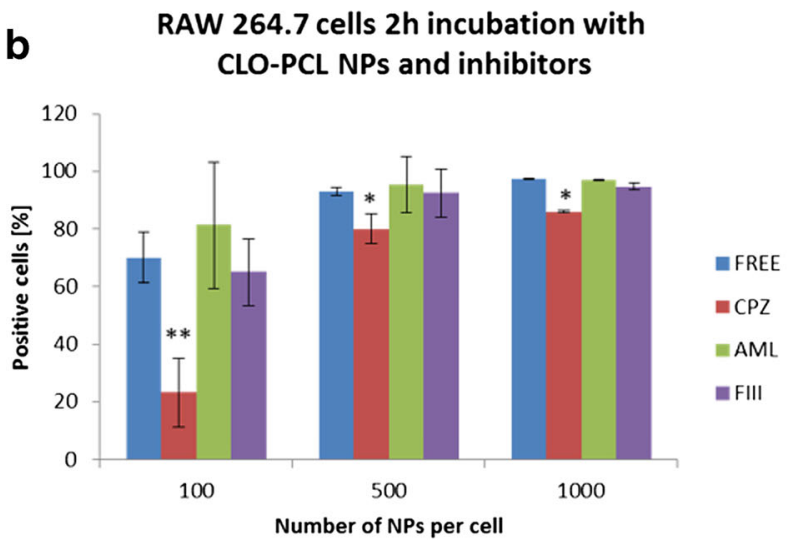

Fig. 5 Internalization studies of both types (non- and pegylated) CLO-PCL NPs by RAW 264.7 cells (flow cytometry analysis). a Dependence of NPs dose. b, c NPs internalization following

(Eigenmann et al. 2013; Weksler et al. 2013); however, the human hCMEC/D3 cell line which was generated by immortalizing primary human brain endothelial cells (Weksler et al. 2013) seems to be the best characterized. The cells have morphology corresponding to primary cells, high transendothelial electrical resistance (TEER)

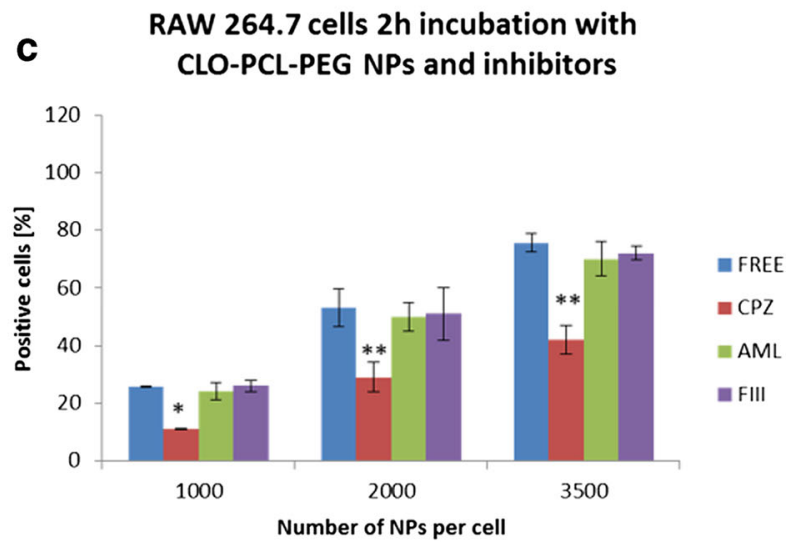

incubation with specific endocytosis inhibitors. Data are presented as the means \pm standard error (SEM)

as well as express important BBB proteins engaged in the formation of tight junction and efflux transporters [73]. In our laboratory, we have a long-term experience in working with the above-mentioned cell line; therefore, all experiments were performed using this model. The biocompatibility experiments performed using
Fig. 6 Cell viability studies in hCMEC/D3 cells after $24 \mathrm{~h}$ incubation with both types (nonand pegylated) CLO-PCL NPs. Data are presented as the means \pm standard error (SEM)

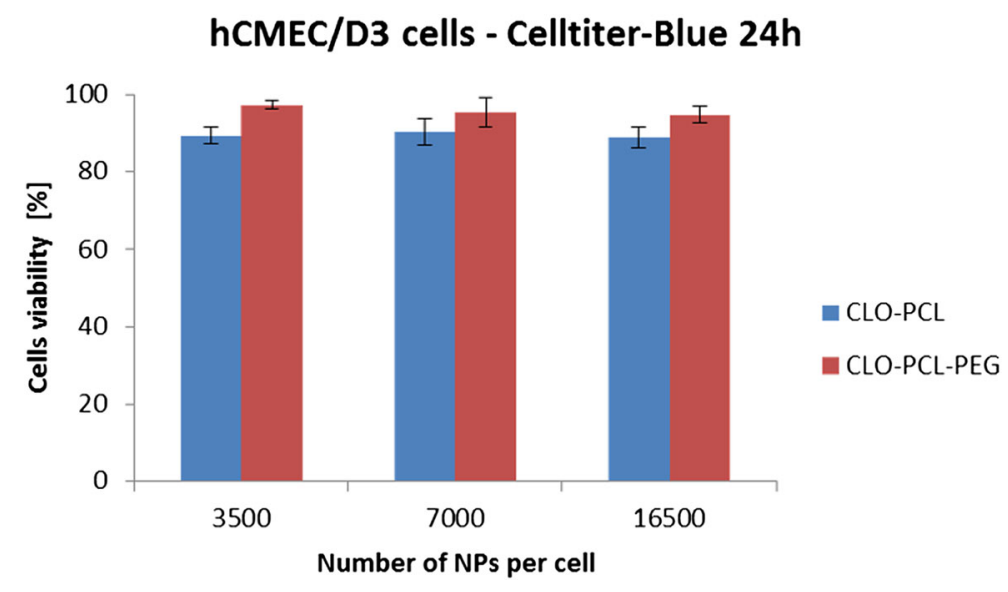


Fig. 7 Internalization studies of both types (non- and pegylated) CLO-PCL NPs by hCMEC/D3 cells (flow cytometry analysis). Dependence of dose and internalization following incubation with specific endocytosis inhibitors. Data are presented as the means \pm standard error (SEM)
NPs internalization - hCMEC/D3 cells

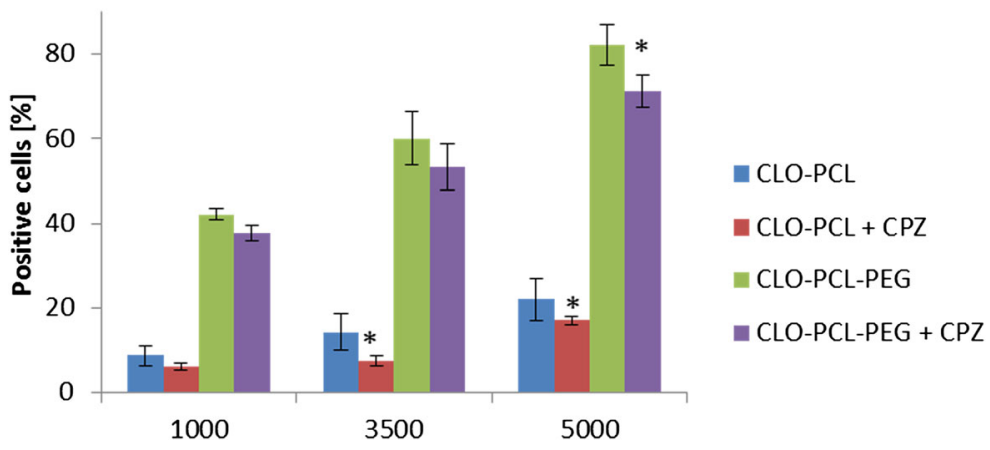

CellTiter-Blue assay indicated that synthesized CLOPCL NPs did not cause substantial decrease of cell viability. Although not statistically different, pegylated CLO-PCL NPs seemed better. Additionally, we did not observe dose dependence. In Fig. 6, the summary of the results is presented.

To quantify the CLO-PCL NPs uptake by hCMEC/ D3 cells, the flow cytometry technique was used. Validation of the method was extremely important since the experiments should be performed only when the hCMEC/D3 achieve the proper density level which enables them to create a BBB model. The preliminary experiments were done according to previously described (Łukasiewicz et al. 2017). When data were acquired at $4{ }^{\circ} \mathrm{C}$, internalization process was hindered, but after the temperature raised to $37^{\circ} \mathrm{C}$, the NPs were uptaken again which suggested that the process was energy-dependent. Based on obtained results (Fig. 7), we can say that internalization occurred via endocytosis mediated by clathrin-coated pits formation.

Moreover, the internalization process was dependent on the used NPs dose. Non-pegylated CLOPCL NPs were taken up to the greatest extent. The difference between both forms of NPs used may result from the surface charge of the particles. Pegylated CLO-PCL NPs have twofold lower negative charge than unmodified ones. It has been shown that molecules with more negative charge are more efficiently taken up by BBB model cells (Kulkarni and Feng 2013). Although pegylated CLO-PCL NPs were less efficiently internalized by hCMEC/D3 cells, we can still influence the process by modifying NPs dose and eventually achieve desired level of the process.

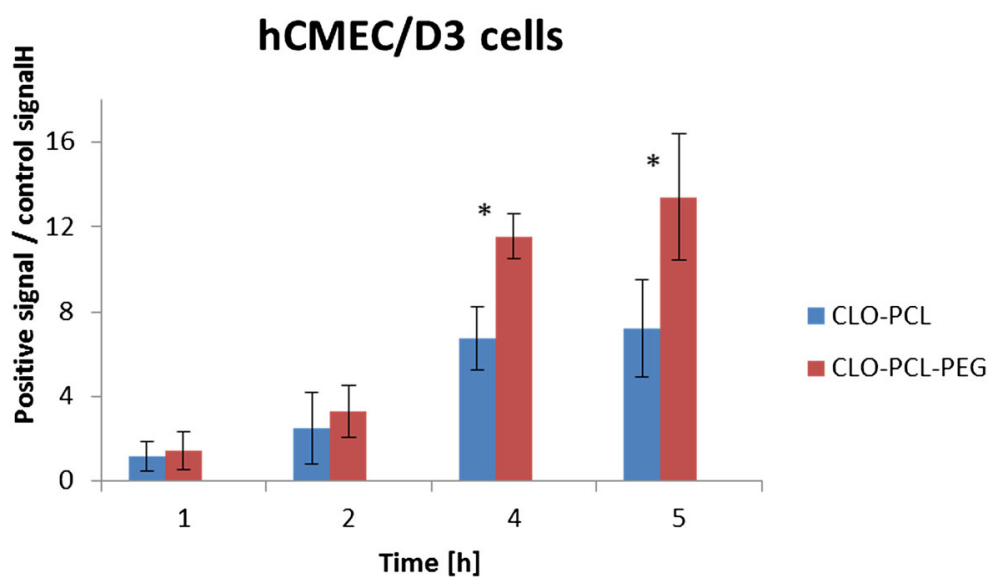

Fig. 8 Transcytosis studies reflected the feasibility of BBB crossing by both types (non- and pegylated) CLO-PCL NPs in hCMEC/ D3 cells - (transwell pore- $3 \mu \mathrm{m}$ ). Similar results were observed for $1 \mu \mathrm{m}$ pore size. Y axis - the ratio of positive signal acquired

from basolateral part of transwell insert after incubation of the hCMEC/D3 cells with coumarin-labelled NPs to signal acquired from basolateral part of transwell insert characteristic for cells which were not incubated with NPs 
To achieve brain areas, nanocarriers have to be able to cross BBB. Because CLO-PCL NPs seem very promising candidates for CLO delivery, we decided to check if our nanoformulations could pass through BBB. Therefore, transcytosis process was investigated. The surface modification of NPs which determined interaction with cell membrane influences the process. The study was performed in two different transwell systems and inserts ( 1 and $3 \mu \mathrm{m}$ pore size) and the obtained results were similar. We observed time dependency. Moreover, pegylation of CLO-PCL NPs facilitated the BBB passage in the in vitro model. In Fig. 8, the final data are presented.

\section{Conclusion}

Both obtained CLO-PCL NPs (pegylated and nonpegylated) have been tested for their possible use as a novel nanoformulation of CLO. To achieve safe and efficient targeted therapy using nanoparticulate system, the wide knowledge of the behaviour of the nanocarrier in contact with model cells is necessary. The results obtained in the present study indicate pegylated CLOPCL NPs (PEG CLO-PCL NPs) as a promising nanovehicles. They were not toxic to model cells. Pegylated outer surface protected from their fast uptake by macrophages. They were not immunogenic (the immunomodulatory effect of clozapine was abolished). Transcytosis experiments pointed to their ability to cross a BBB model. The presented experiments were conducted only in the in vitro model but they provide valuable data in the field of nanotechnology and its use in novel molecular pharmacology.

Funding The research has received funding from the PolishNorwegian Research Programme operated by the National Centre for Research and Development under the Norwegian Financial Mechanism 2009-2014 in the frame of Project Contract No PolNor/199523/64/2013 NanoNeucar. The funding sources had no further role in the design of the study, the collection, analysis and interpretation of the data, the writing of the report, and the decision to submit the paper for publication. The Faculty of Biochemistry, Biophysics and Biotechnology and Jerzy Haber Institute of Catalysis and Surface Chemistry PAS are partners with the Leading National Research Center (KNOW) supported by the Ministry of Science and Higher Education.

\section{Compliance with ethical standards}

Conflict of interest The authors declare that they have no conflict of interest.
Open Access This article is distributed under the terms of the Creative Commons Attribution 4.0 International License (http:// creativecommons.org/licenses/by/4.0/), which permits unrestricted use, distribution, and reproduction in any medium, provided you give appropriate credit to the original author(s) and the source, provide a link to the Creative Commons license, and indicate if changes were made.

\section{References}

Abedini F, Ebrahimi M, Roozbehani AH, Domb A, Hosseinkhani H (2018) Overview on natural hydrophilic polysaccharide polymers in drug delivery. Polym Adv Technol 29:25642573. https://doi.org/10.1002/pat.4375

Agrahari V, Agrahari V, Hung WT, Christenson LK, Mitra AK (2016) Composite nanoformulation therapeutics for longterm ocular delivery of macromolecules. Mol Pharm 6: 2912-2922. https://doi.org/10.1021/acs.molpharmaceut.5 b00828

Alexis F, Pridgen E, Molnar LK, Farokhzad OC (2008) Factors affecting the clearance and biodistribution of polymeric nanoparticles. Mol Pharm 5:505-515. https://doi. org/10.1021/mp800051m

Ali FT, Abd El-Azeem EM, Hamed MA, Ali MAM, Abd AlKader NM, Hassan EA (2017) Redox dysregulation, immuno-inflammatory alterations and genetic variants of BDNF and MMP-9 in schizophrenia: pathophysiological and phenotypic implications. Schizophr Res 188:98-109. https://doi.org/10.1016/j.schres.2017.01.016

Alibolandi M, Abnous K, Ramezani M, Hosseinkhani H, Hadizadeh F (2014) Synthesis of AS1411-aptamerconjugated $\mathrm{CdTe}$ quantum dots with high fluorescence strength for probe labeling tumor cells. J Fluoresc 24:15191529. https://doi.org/10.1007/s10895-014-1437-5

Alibolandi M, Abnous K, Sadeghi F, Hosseinkhani H, Ramezani M, Hadizadeh F (2016) Folate receptor-targeted multimodal polymersomes for delivery of quantum dots and doxorubicin to breast adenocarcinoma: in vitro and in vivo evaluation. Int J Pharm 16:162-178. https://doi.org/10.1016/j. ijpharm.2016.01.040

Anton N, Saulnier C, Gaillard E, Porcher S, Vrignaud S, Benoit J (2009) Aqueous-core lipid nanocapsules for encapsulating fragile hydrophilic and/or lipophilic molecules. Langmuir 25:11413-11419. https://doi.org/10.1021/la901565q

Berardis D, Serroni N, Campanella D, Olivieri L, Ferri F, Carano A, Cavuto M, Martinotti G, Cicconetti A, Piersanti M, Saverio Moschetta F, Di Giannantonio M (2012) Update on the adverse effects of clozapine: focus on myocarditis. Curr Drug Saf 7:55-62

Berardis D, Rapini G, Olivieri L, Nicola D, Tomasetti C, Valchera A, Fornaro M, Fabio F, Perna G, Nicola M, Serafini G, Carano A, Pompili M, Vellante F, Orsolini L, Martinotti G, Giannantonio M (2018) Safety of antipsychotics for the treatment of schizophrenia: a focus on the adverse effects of clozapine. Ther Adv Drug Saf 9:237-256. https://doi. org/10.1177/2042098618756261

Chen ML, Wu S, Tsai TC, Wang LK, Tsai FM (2013) Regulation of macrophage immune responses by antipsychotic drugs. 
Immunopharmacol Immunotoxicol 35:573-580. https://oi. org/10.3109/08923973.2013.828744

da Costa Güllich AA, Coelho RP, Pilar BC, Ströher DJ, Galarça LA, Vieira SM, da Costa Escobar Piccoli J, Haas SE, Manfredini V (2015) Clozapine linked to nanocapsules minimizes tissue and oxidative damage to biomolecules lipids, proteins and DNA in brain of rats Wistar. Metab Brain Dis 30:695-702. https://doi.org/10.1007/s11011-014-9621-5

De Berardis D, Serroni N, Campanella D, Olivieri L, Marini S, Moschetta FS, Martinotti G, Di Giannantonio M (2013) Safety and efficacy of combined clozapineazathioprine treatment in a case of resistant schizophrenia associated with Behcet's disease: a 2-year follow-up. Gen Hosp Psychiatry 35:213e9-213e11. https://doi.org/10.1016/j. genhosppsych.2012.06.007

Eigenmann DE, Xue G, Kim KS, Moses AV, Hamburger M, Oufir M (2013) Comparative study of four immortalized human brain capillary endothelial cell lines, hCMEC/D3, hBMEC, TY10, and BB19, and optimization of culture conditions, for an in vitro blood-brain barrier model for drug permeability studies. Fluids Barriers CNS 10:33-8118-10-33. https://doi. org/10.1186/2045-8118-10-33

Essali A, Al-Haj Haasan N, Li C, Rathbone J (2009) Clozapine versus typical neuroleptic medication for schizophrenia. Cochrane Database Syst Rev (1):CD000059

Farokhi M, Mottaghitalab F, Shokrgozar MA, Ou KL, Mao C, Hosseinkhani H (2016) Importance of dual delivery systems for bone tissue engineering. J Control Release 10:152-169. https://doi.org/10.1016/j.jconrel.2016.01.033

Fond G, Macgregor A, Miot S (2013) Nanopsychiatry-the potential role of nanotechnologies in the future of psychiatry: a systematic review. Eur Neuropsychopharmacol 23:10671071. https://doi.org/10.1016/j.euroneuro.2012.10.016

Francesconi LP, Victorino AT, Salah IA, Cordova VH, Dias da Rosa E, Oliveira L, Jacobus RVM, Belmonte-de-Abreu PS, Ceresér KM (2018) Proinflammatory and anti-inflammatory biomarkers in schizophrenia and influence of simvastatin on the interleukin-6. Int Clin Psychopharmacol 19:84-88. https://doi.org/10.1097/YIC.0000000000000241

Ghadiri M, Vasheghani-Farahani E, Atyabi F, Kobarfard F, Mohamadyar-Toupkanlou F, Hosseinkhani H (2017) Transferrin-conjugated magnetic dextran-spermine nanoparticles for targeted drug transport across blood-brain barrier. J Biomed Mater Res A 105:2851-2864. https://doi. org/10.1002/jbm.a.36145

Halperin A (1999) Polymer brushes that resist adsorption of model proteins: design parameters. Langmuir 15:2525-2533

Hong S, Leroueil PR, Janus EK, Peters JL, Kober M, Islam MT, Orr BG, Baker JR, Banaszak MM (2006) Interaction of polycationic polymers with supported lipid bilayers and cells: nanoscale hole formation and enhanced membrane permeability. Bioconjug Chem 17:728-734. https://doi. org/10.1021/bc060077y

Howes OD, McCutcheon R, Agid O (2017) Treatment-resistant schizophrenia: treatment response and resistance in psychosis (TRRIP) working group consensus guidelines on diagnosis and terminology. Am J Psychiatry 174:216-229. https://doi. org/10.1176/appi.ajp.2016.16050503

Kadam RS, Bourne DW, Kompella UB (2012) Nano-advantage in enhanced drug delivery with biodegradable nanoparticles: contribution of reduced clearance. Drug Metab Dispos 40: 1380-1388. https://doi.org/10.1124/dmd.112.044925

Khan W, Hosseinkhani H, Ickowicz D, Hong PD, Yu DS, Domb AJ (2012) Polysaccharide gene transfection agents. Acta Biomater 8:4224-4232. https://doi.org/10.1016/j. actbio.2012.09.022

Khan IU, Serra CA, Anton N, Vandamme TF (2015) Production of nanoparticle drug delivery systems with microfluidics tools. Expert Opin Drug Deliv 12:547-562

Kim SS, Rait A, Kim E, DeMarco J, Pirollo KF, Chang EH (2015) Encapsulation of temozolomide in a tumor-targeting nanocomplex enhances anti-cancer efficacy and reduces toxicity in a mouse model of glioblastoma. Cancer Lett 1:250 258. https://doi.org/10.1016/j.canlet.2015.08.022

Kiran ASK, Kumar TSS, Sanghavi R, Doble M, Ramakrishna S (2018) Antibacterial and bioactive surface modifications of titanium implants by $\mathrm{PCL} / \mathrm{TiO}_{2}$ nanocomposite coatings. Nanomaterials (Basel) 8. https://doi.org/10.3390 /nano8100860

Kirbay O, Geyik C, Guler E, Yesiltepe O, Gumus ZP, Demirkol O, Coskunol H, Timur S (2017) Testing of bioactivenanovesicles on hepatotoxicity of atypical antipsychotics via digital holography. Colloids Surf B Biointerfaces 1: 289-295. https://doi.org/10.1016/j.colsurfb.2017.01.006

Kulkarni AS, Feng SS (2013) Effects of particle size and surface modification on cellular uptake and biodistribution of polymeric nanoparticles for drug delivery. Pharm Res 30:25122522. https://doi.org/10.1007/s11095-012-0958-3

Lee H, Larson RG (2008) Lipid bilayer curvature and pore formation induced by charged linear polymers and dendrimers: the effect of molecular shape. J Phys Chem B 112:12279-12285. https://doi.org/10.1021/jp805026m

Leroueil PR, Berry SA, Duthie K, Han G, Rotello VM, McNerny DQ, Baker JR, Orr BG, Banaszak Holl MM (2008) Wide varieties of cationic nanoparticles induce defects in supported lipid bilayers. Nano Lett 8:420-424. https://doi.org/10.1021 /n10722929

Li A, Yang F, Xin J, Bai X (2019) An efficient and long-acting local anesthetic: ropivacaine-loaded lipid-polymer hybrid nanoparticles for the control of pain. Int J Nanomedicine 31:913-920. https://doi.org/10.2147/IJN.S190164

Łukasiewicz S, Szczepanowicz K, Błasiak E, DziedzickaWasylewska M (2015) Biocompatible polymeric nanoparticles as promising candidates for drug delivery. Langmuir. 31 : 6415-6425. https://doi.org/10.1021/acs.langmuir.5b01226

Łukasiewicz S, Szczepanowicz K, Podgórna K, Błasiak E, Majeed N, Ogren SO, Nowak W, Warszyński P, DziedzickaWasylewska M (2016) Encapsulation of clozapine in polymeric nanocapsules and its biological effects. Colloids Surf B Biointerfaces 140:342-352. https://doi.org/10.1016/j. colsurfb.2015.12.044

Łukasiewicz S, Błasiak E, Szczepanowicz K, Guzik K, Bzowska M, Warszyński P, Dziedzicka-Wasylewska M (2017) The interaction of clozapine loaded nanocapsules with the hCMEC/D3 cells - in vitro model of blood brain barrier. Colloids Surf B Biointerfaces 1:200-210. https://doi. org/10.1016/j.colsurfb.2017.07.053

Lupi M, Colombo C, Frapolli R, Ferrari R, Sitia L, Dragoni L, Bello E, Licandro AS, Falcetta F, Ubezio P, Bigini P, Salmona M, D'Incalci M, Morbidelli M, Moscatelli D (2014) A biodistribution study of PEGylated PCL-based 
nanoparticles in C57BL/6 mice bearing B16/F10 melanoma. Nanotechnology 25:335706. https://doi.org/10.1088/09574484/25/33/335706

Maghraby GM, Williams AC, Barry BW (2006) Can drug-bearing liposomes penetrate intact skin? J Pharm Pharmacol 58:415429. https://doi.org/10.1211/jpp.58.4.0001

Mainardes RM, Silva LP (2004) Drug delivery systems: past, present, and future. Curr Drug Targets 5:449-455

Manjunath K, Venkateswarlu V (2005) Pharmacokinetics, tissue distribution and bioavailability of clozapine solid lipid nanoparticles after intravenous and intraduodenal administration. J Control Release 107:215-228. https://doi.org/10.1016/j. jconrel.2005.06.006

Mathaes R, Winter G, Besheer A, Engert J (2014) Influence of particle geometry and PEGylation on phagocytosis of particulate carriers. Int J Pharm 25:159-164. https://doi. org/10.1016/j.ijpharm.2014.02.037

Meltzer HY, Huang M (2008) In vivo actions of atypical antipsychotic drug on serotonergic and dopaminergic systems. Prog Brain Res 172:177-197. https://doi.org/10.1016/S0079-6123 (08)00909-6

Milton Harris J, Chess RB (2003) Effect of pegylation on pharmaceuticals. Nat Rev Drug Discov 2:214-221. https://doi. org $/ 10.1038 / \mathrm{nrd} 1033$

Moraes BS, Vieira SM, Salgueiro WG, Michels LR, Colomé LM, Avila DS, Haas SE (2016) Clozapine-loaded polysorbatecoated polymeric nanocapsules: physico-chemical characterization and toxicity evaluation in Caenorhabditis elegans model. J Nanosci Nanotechnol 16:1257-1264

Mottaghitalab F, Farokhi M, Shokrgozar MA, Atyabi F, Hosseinkhani H (2015) Silk fibroin nanoparticle as a novel drug delivery system. J Control Release 28:161-176. https://doi.org/10.1016/j.jconrel.2015.03.020

Muthupandian S, Barik K, Mubarak D, Pugazhendhi A, Prakash P (2018) Synthesis of silver nanoparticles from Bacillus brevis (NCIM 2533) and their antibacterial activity against pathogenic bacteria. Microb Pathog 1:116-226. https://doi. org/10.1016/j.micpath.2018.01.038

Nel A, Xia T, Mädler L, Li N (2006) Toxic potential mater. Nanolevel. 311:622-627

Omarch F, Kippie Y, Mentor S, Ebrahim N, Fisher D, Murilla G, Swai H, Dube A (2019) Comparative in vitro transportation of pentamidine across the blood-brain barrier using polycaprolactone nanoparticles and phosphatidylcholine liposomes. Artif Cells Nanomed Biotechnol 47:1428-1436. https://doi.org/10.1080/21691401.2019.1596923

Orsolini L, Tomasetti C, Valchera A, Vecchiotti R, Matarazzo I, Vellante F, Iasevoli F, Buonaguro EF, Fornaro M, Fiengo AL, Martinotti G, Mazza M, Perna G, Carano A, De Bartolomeis A, Di Giannantonio M, De Berardis D (2016) An update of safety of clinically used atypical antipsychotics. Expert Opin Drug Saf 15:1329-1347. https://doi.org/10.1080 $/ 14740338.2016 .1201475$

Owens DE, Peppas NA (2006) Opsonization, biodistribution, and pharmacokinetics of polymeric nanoparticles. Int J Pharm 307:93-102. https://doi.org/10.1016/j.ijpharm.2005.10.010

Panda A, Meena J, Katara R, Majumdar DK (2016) Formulation and characterization of clozapine and risperidone co-entrapped spray-dried PLGA nanoparticles. Pharm Dev Technol 21:4353. https://doi.org/10.3109/10837450.2014.965324
Pang Z, Lu W, Gao H, Hu K, Chen J, Zhang C, Gao X, Jiang X, Zhu C (2008) Preparation and brain delivery property of biodegradable polymersomes conjugated with OX26. J Control Release 4:120-127. https://doi.org/10.1016/j. jconrel.2008.03.007

Peng W, Jiang XY, Zhu Y, Omari-Siaw E, Deng WW, Yu JN, Xu XM, Zhang WM (2015) Oral delivery of capsaicin using MPEG-PCL nanoparticles. Acta Pharmacol Sin 26:139148. https://doi.org/10.1038/aps.2014.113

Pollmächer T, Schuld A, Kraus T, Haack M, Hinze-Selch D (2001) On the clinical relevance of clozapine-triggered release of cytokines and soluble cytokine-receptors. Fortschr Neurol Psychiatr 69:65-74. https://doi.org/10.1055/s-2001-16533

Remington G, Lee J, Agid O, Takeuchi H, Foussias G, Hahn M, Fervaha G, Burton L, Powell H (2016) Clozapine's critical role in treatment resistant schizophrenia: ensuring both safety and use. Exp Opin Drug Saf 15:1193-1203. https://doi. org/10.1080/14740338.2016.1191468

Saravanan M, Jacob V, Arockiaraj J, Prakas P (2014) Extracellular biosynthesis, characterization and antibacterial activity of silver nanoparticles synthesized by Bacillus subtilis (NCIM-2266). J Bionanosci 8:1-7. https://doi.org/10.1166 /jbns.2014.1201

Siskind D, McCartney L, Goldschlager R (2016) Clozapine v. first- and second-generation antipsychotics in treatmentrefractory schizophrenia: systematic review and metaanalysis. Br J Psychiatry 209:385-392

Stępnicki P, Kondej M, Kaczor AA (2018) Current concepts and treatments of schizophrenia. Molecules. 23. https://doi. org/10.3390/molecules23082087

Szczęch M, Szczepanowicz K, Jantas D, Piotrowski M, Kida A, Lasoń W, Warszyński P (2017) Neuroprotective action of undecylenic acid (UDA) encapsulated into PCL nanocarriers. Colloids Surf Physicochem Eng Aspects 537:41-47

Torchilin VP, Trubetskoy VS (1995) Which polymers can make nanoparticulate drug carriers long-circulating? Adv Drug Deliv Rev 16:141-155

Verma A, Stellacci F (2010) Effect of surface properties on nanoparticle? Cell interactions. Small. 6:12-21

Vermette P, Meagher L (2003) Interactions of phospholipid- and poly(ethylene glycol)-modified surfaces with biological systems: relation to physico-chemical properties and mechanisms. Colloids Surf B Biointerfaces 28:153-198

Vieira SM, Michels LR, Roversi K, Metz VG, Moraes BK, Piegas EM, Freddo RJ, Gundel A, Costa TD, Burger ME, Colomé LM, Haas SE (2016) A surface modification of clozapineloaded nanocapsules improves their efficacy: a study of formulation development and biological assessment. Colloids Surf B Biointerfaces 1:748-756. https://doi. org/10.1016/j.colsurfb.2016.05.065

Warnez S, Alessi-Severini S (2014) Clozapine: a review of clinical practice guidelines and prescribing trends. BMC Psychiatry 14:102-244X-14-102. https://doi.org/10.1186/1471-244X14-102

Weksler B, Romero IA, Couraud PO (2013) The hCMEC/D3 cell line as a model of the human blood brain barrier. Fluids Barriers CNS 10:16-8118-10-16. https://doi.org/10.1186 /2045-8118-10-16

Wilczewska AZ, Niemirowicz K, Markiewicz KH, Car H (2012) Nanoparticles as drug delivery systems. Pharmacol Rep 64: 1020-1037 
Xie X, Song J, Hu Y, Zhuang S, Wang Y, Zhao Y, Lu Q (2018) Tailor-made PL-UC-C3 nanoparticles for fluorescence/ computed tomography imaging-guided cascade amplified photothermal therapy. Int J Nanomedicine 13:7633-7646. https://doi.org/10.2147/IJN.S188169

Xin X, Sha X, Jiang X, Zhang W, Chen L, Fang X (2012) Antiglioblastoma efficacy and safety of paclitaxel-loading Angiopep-conjugated dual targeting PEG-PCL nanoparticles. Biomaterials 33:8167-8176. https://doi.org/10.1016/j. biomaterials.2012.07.046

Yeste J, Ill X, Alvarez M, Villa R (2018) Engineering and monitoring cellular barrier models. J Biol Eng 12:12-18. https://doi.org/10.1186/s13036-018-0108-5

Zhang Y, Kohler N, Zhang M (2002) Surface modification of superparamagnetic magnetite nanoparticles and their intracellular uptake. Biomaterials 23:1553-1561
Zhu B, Eurell T, Gunawan R, Leckband D (2001) Chain-length dependence of the protein and cell resistance of oligo(ethylene glycol)-terminated self-assembled monolayers on gold. J Biomed Mater Res 56:406-416

Zhukova Y, Skorb EV (2017) Cell guidance on nanostructured metal based surfaces. Adv Healthc Mater 6. https://doi. org/10.1002/adhm.201600914

Publisher's note Springer Nature remains neutral with regard to jurisdictional claims in published maps and institutional affiliations. 